\title{
Nutritional Status of Pupils Attending Public Schools with and without School Feeding Programme in Hohoe Municipality, Ghana
}

\author{
Faith Agbozo ${ }^{1,2, *}$, Prosper Atitto ${ }^{1}$, Abdulai Abubakari ${ }^{3}$ \\ ${ }^{1}$ Department of Family and Community Health, School of Public Health, University of Health and Allied Sciences, Ho, Ghana \\ ${ }^{2}$ Institute of Public Health, University of Heidelberg, Heidelberg, Germany \\ ${ }^{3}$ Community Nutrition Department, School of Allied Health Sciences, University for Development Studies, Ghana \\ *Corresponding author: faagbozo@uhas.edu.gh
}

\begin{abstract}
At-school lunch provision through the Ghana school-feeding programme (GSFP) is a child survival, health promotion and food security intervention implemented in selected schools in all 216 districts nationwide with the nutrition objective of reducing short-term hunger and malnutrition. The study assessed the impact of the Ghana School Feeding Programme (GSFP) on the nutritional status of participants. School-based cross-sectional survey using multi-stage sampling to select 417 pupils aged 3-12 years enrolled in 14 public basic schools with ( $\mathrm{n}=133)$ and without $(n=304)$ school feeding programme in the seven sub-districts of the Hohoe municipality, Ghana. Data was collected between January-April 2015 through face-to-face interviews using a semi-structured questionnaire with assistance from teachers/guardians. Weight, height and mid upper-arm circumference were measured and used to generate underweight, stunting, thinness and obesity using WHO Antroplus and STATA 12.1. Mutually-adjusted simple and multinomial logistic regressions were done to determine association between the explanatory and dependent variables. Overall, $15.6 \%$ underweight, 9.8\% stunting, $4.3 \%$ thinness and $5.5 \%$ overweight prevalence were observed. Between beneficiary and non-beneficiary pupils, there were no statistically significant differences in underweight (12.4\% vs. $16.8 \%)$, stunting ( $13.3 \%$ vs. $8.6 \%)$, thinness $(1.8 \%$ vs. $5.3 \%)$ and overweight $(3.5 \%$ vs. $5.6 \%)$ respectively. Most of the explanatory variables including provision of schools meals were not significantly associated with the nutritional status indicators. Pupils in lower primary had increase odds for underweight (AOR; $3.0,95 \% \mathrm{CI} ; 1.4-6.6, \mathrm{p}=0.006$ ) while those residing in rural areas were five folds more likely to be stunted (AOR; $5.3,95 \% \mathrm{CI} ; 1.3-21.6, \mathrm{p}=0.021$ ). Prevalence of malnutrition was lower among beneficiaries but there were no statistical significant differences in anthropometry between schools with and without feeding programme. Findings suggest that the school feeding programme could marginally improve nutritional status of beneficiaries.
\end{abstract}

Keywords: school feeding programme, Ghana, nutritional status, anthropometry, school meals, school age children, malnutrition

Cite This Article: Faith Agbozo, Prosper Atitto, and Abdulai Abubakari, "Nutritional Status of Pupils Attending Public Schools with and without School Feeding Programme in Hohoe Municipality, Ghana." Journal of Food and Nutrition Research, vol. 5, no. 7 (2017): 467-474. doi: 10.12691/jfnr-5-7-3.

\section{Introduction}

Childhood malnutrition is a public health problem in most developing countries with adverse consequences on the socio-economic development of nations. Globally, a quarter of children under-five years are stunted with $15 \%$ underweight, $8 \%$ wasted and $6 \%$ overweight. Prevalence of overweight in Sub-Saharan Africa is same as the global situation. However, there are higher levels of stunting (37\%), underweight (21\%) and wasting (9\%) [1]. In recent years in Ghana, substantial progress has been achieved in reducing undernutrition among children under 5 five years. The 2014 Ghana demographic and health survey revealed a stunting prevalence of $19 \%$, wasting $5 \%$ and underweight $11 \%$ [2]. This is a decrease from the $28 \%$ stunting, 9\% wasting and 14\% underweight prevalence recorded in 2008 [3]. This decrease is the result of interventions initiated by the government in collaboration with international organizations to curtail causes and effects of childhood undernutrition. Some of these interventions include growth monitoring and promotion, vitamin A supplementation, school-based nutrition education, deworming, and school feeding programme (SFP). Despite this progress, there are still pockets of high under nutrition $[2,4]$.

Ghana is one of the 169 countries that provide daily meals to about 368 million children globally while at school [5]. The Ghana school-feeding programme (GSFP) was initiated by the Government in late 2005 in ten pilot schools covering 64,775 beneficiary pupils. Currently, the programme is implemented in all 216 districts. At the end of 2012, 1.64 million pupils were beneficiaries of the 
programme [6]. Children in selected public kindergarten and primary schools are provided with at-school lunch meals every school day using locally grown foods as a means of contributing to poverty reduction and food security in the long-term. The programme has three pivotal objectives: to increase school enrolment, attendance and retention; reduce short-term hunger and malnutrition; and boost agriculture and domestic food production. Provision of school meals is thus a health improvement and child survival intervention strategy. Yet coverage as at 2013 was less than $10 \%$ [5].

Generally, literature on the impact of school feeding programmes has shown varied outcomes. For instance, impact on school enrolment and attendance has been conclusive [7-13]. However, dietary quality of school meals $[14,15,16]$, nutritional status $[8,17,18,19]$ and academic achievement $[20,21,22]$ of school-aged children receiving school meals compared to non-school-fed children have been inconclusive. Similarly, in sub-Saharan Africa, evidence on the impact of provision of school meals on growth of participating school children has also showed varied outcomes. In Malawi for instance, after one school year follow-up, mid-upper arm circumference (MUAC) of participating children increased from $16.3 \mathrm{~cm}$ to $17.0 \mathrm{~cm}$ [23].

Monitoring and evaluation of impact of the SFP in Ghana have mostly focused on school enrolment, attendance and retention of school age children in schools as outcome measures $[24,25,26,27]$. Consequently, findings from several studies have justified the expansion of the programme based on these outcome measures. A few studies have examined other impacts relating to community involvement in implementation and socioeconomic effects of the programme [28,29,30]. Few studies have also assessed impact of the programme on anthropometry. A study conducted in 2012 in AtwimaNwabiagya District of the Ashanti Region aimed at assessing the nutritional status of participating and nonparticipating school children aged 9 to 17 years did not find any statistically significant difference in the anthropometric measurements between the two groups [4]. In northern Ghana, although provision of school meals contributed to significantly higher energy and micronutrient intakes among participants, there were no differences in the prevalence of thinness, underweight and stunting among the participating and non-participating school children [31]. In some instances, prevalence of undernutrition was even higher among children enrolled in schools on feeding programme [32].

To ameliorate the financial, personnel, technical and policy challenges associated with implementation of school feeding programmes, a number of strategies have been recommended. These include monitoring and evidence-based impact evaluation of focal areas of school feeding programmes [8,33], integration with other programmes, improving intersectoral decision making [15], and clear policy direction on the implementation process [13]. In Ghana, evaluation of the SPF has focused mostly on impact on enrolment and attendance. Since reduction of malnutrition is a core objective of the programme, it is important that this objective is routinely evaluated to assess the level of achievement. It is against this background that this study was conducted to assess the effects of enrolment in schools in which free meals are provided on the levels of underweight, stunting, wasting and overweight between beneficiary and non-beneficiary school children.

\section{Methods}

\subsection{Study Area}

The study was conducted in the Hohoe municipality, one of the 25 administrative districts in the Volta region of Ghana. The municipality is situated in the middle of the region with an estimated population of 167,016 inhabitants comprising $52.1 \%$ females and $47.9 \%$ males living in over 180 rural (47.4\%) and urban (52.6\%) communities. The population of the municipality is youthful with $35.9 \%$ under age 15 years [34]. The municipality covers a total land area of 1,172 square kilometres and divided into seven zones called sub-districts for administrative purposes. These seven sub-districts are; Akpafu, Agumatsa, Alavanyo, Gbi, Lolobi, Hohoe and Likpe. Hohoe sub-district is urban; some parts of Gbi and Likpe are peri-urban while the remaining ones are rural. However, schools with meals were evenly distributed over both rural (27.6\%) and urban (26.5\%) areas.

\subsection{Design, Target Population and Sampling}

An exploratory school-based cross-sectional design was used. The target population was school age children enrolled in public (state-owned) basic schools within the Hohoe municipality. In Ghana, basic schools provide formal education that entails foundation courses starting from kindergarten to the junior high school level. The Ghana School Feeding Programme (GSFP) covers public basic school pupils from kindergarten to primary six who are usually within the ages of 3-12 years. Pupils in kindergarten are preschoolers while those from primary one to six are school age children with primary one to three termed lower primary and primary four to six termed upper primary. There are 69 public basic schools within the Hohoe municipality with a total population of 17,265 pupils out of which 15 are participating in the GFSP with about 4,000 beneficiary pupils constituting approximately one-fourth of the pupil population.

The sample size was determined using alpha of 1.96 at $95 \%$ confidence interval with a permitted 3\% margin of error considering a $17 \%$ [2] population prevalence of undernutrition. This generated a sample size of 417. A multi-stage sampling method was used in the selection of study schools and participants. There are seven sub-districts in the municipality. To get a representative sample, the seven sub-districts were considered as clusters. Two public primary schools were randomly selected from each cluster; one implementing the GSFP and another without any school feeding programme as control. Within the schools, each level from kindergarten to primary six was treated as a stratum. Using the class register as the sampling frame, proportionate number of males and females were systematically sampled from each stratum. Only pupils who were enrolled in the schools for at least one academic year were eligible to be included in the study. 


\subsection{Data Collection Tools and Procedures}

Data was collected at the second term of the 2015 academic year specifically from January to April through face-to-face interviews using a semi-structured questionnaire designed to achieve the objectives of the study. Participants in upper primary were personally interviewed whereas parents and guardians and sometimes teachers of pupils in kindergarten and lower primary were invited to provide responses to the interviews. Responses elicited included age, class, occupation of the child's guardian, and frequency of fruit and breakfast consumption by the child per week. Anthropometric measurements were taken following WHO standard anthropometry guidelines. Height was measured using 'SECA' stadiometre to the nearest 0.1 centimetres, weight using digital weighing scale to the nearest 0.1 kilogram and mid-upper arm circumference (MUAC) using non-extensible MUAC tape to the nearest 0.1 millimetres. Measurement errors were reduced by engaging trained nutrition officers employed by Ghana Health Service to assist with data collection.

\subsection{Statistical Analysis}

Weight, height and MUAC measurements were converted to weight-for-age Z-scores (WAZ), height-for-age Z-scores (HAZ), body mass index (BMI), BMI-for-age Z-scores (BAZ) and MUAC-for-age $\mathrm{z}$ scores (MAZ) using WHO Anthroplus software (version 10.4). The resulting indices were used to determine the levels of underweight (WAZ $<-2 \mathrm{SD}$ ), stunting (HAZ $<-2 \mathrm{SD}$ ), thinness (BAZ $<-2$ $\mathrm{SD})$ and overweight (BAZ $>1 \mathrm{SD})$. Data entry and analysis was done using STATA (version 12.1). Both descriptive and inferential statistics were used in analyzing and reporting findings. Differences in participants' characteristics between the intervention and control groups were determined using Pearson's Chi-square test for categorical variables, which were presented as frequencies and proportions. Student's t-test was used for continuous variables involving two categories and reported as means with standard deviations (SD). The association between the explanatory variables under investigation and the dependent variables, that is, underweight and stunting were determined using simple logistic regression. To get the best fit, the regression analysis was mutually adjusted for all the variables included in the model. Multinomial logistic regression model was used to determine the association between BMI-for-age Z-scores (BAZ) and the explanatory variables. This regression was used because the BAZ was classified into three categories; thinness, normal weight and overweight. Differences were significant if $\mathrm{p}<0.05$ at $95 \%$ confidence interval.

\subsection{Ethical Considerations}

The study protocol was reviewed and approved by the Ghana Health Service Ethics Review Committee (ethics approval ID GHS-ERC:15/04/15). Permission was granted by the Municipal Health and Education Directorates of the Hohoe municipality. Informed consent was obtained from parents and guardians of the school children while the participants provided assent to participate in the study.

\section{Results}

Overall, the proportion of the school pupils who were underweight was $15.6 \%$ while those who were stunted were $9.8 \%$. Moreover $4.3 \%$ were thin (wasted) for their age whereas $5.5 \%$ were overweight.

As seen from Table 1, 12.4\% of the pupils who attended schools implementing the Ghana feeding programme were underweight while $16.8 \%$ of those who attended schools without any feeding programme were also underweight. About $13.0 \%$ of beneficiary pupils were stunted as against $8.6 \%$ of non-beneficiary pupils. Thinness was $1.8 \%$ among pupils attending the GSFP schools and 5.3\% among pupils attending schools without the school feeding programme. Moreover, 3.5\% of those attending schools implementing the GSPF were overweight as compared to $5.6 \%$ of pupils attending schools without any feeding programme. However, the differences in underweight, stunting, thinness and overweight observed between the two types of schools were statistically non-significant.

Table 1. Characteristics of study participants based on the type of school attended

\begin{tabular}{|c|c|c|c|c|}
\hline & Variables & School feeding (n/N\%) & Non-school feeding (n/N\%) & P-value $^{1}$ \\
\hline \multirow{4}{*}{ Anthropometry } & Underweight & $44 / 113(12.4)$ & $51 / 304(16.8)$ & 0.272 \\
\hline & Stunting & $15 / 113(13.3)$ & $26 / 304(8.6)$ & 0.150 \\
\hline & Thinness & $2 / 113(1.8)$ & $16 / 304(5.3)$ & 0.119 \\
\hline & Overweight & $4 / 113(3.5)$ & $17 / 304(5.6)$ & 0.394 \\
\hline \multirow{2}{*}{ Sex } & Male & $56 / 206(27.0)$ & $150 / 206(73.0)$ & 0.969 \\
\hline & Female & $57 / 211(27.0)$ & $154 / 211(73.0)$ & \\
\hline \multirow{2}{*}{ Age groups } & $3-5$ & $19 / 78(24.4)$ & $59 / 78(75.6)$ & 0.546 \\
\hline & $6-12$ & $94 / 339(26.7)$ & $245 / 339(73.3)$ & \\
\hline \multirow{3}{*}{ Class } & Kindergarten & $30 / 112(26.8)$ & $82 / 112(73.2)$ & \\
\hline & Lower primary & $42 / 158(26.6)$ & $116 / 158(73.4)$ & 0.964 \\
\hline & Upper primary & $41 / 147(28.0)$ & $106 / 147(72.0)$ & \\
\hline \multirow{2}{*}{ Geographic location } & Rural & $79 / 291(27.0)$ & $212 / 291(73.0)$ & 0.972 \\
\hline & Urban & $34 / 126(27.0)$ & $92 / 126(73.0)$ & \\
\hline \multirow{5}{*}{ Guardian's Occupation } & Formal & $5 / 22(22.7)$ & $17 / 22(77.3)$ & \\
\hline & Petty trader & $30 / 135(22.2)$ & $105 / 135(77.8)$ & \\
\hline & Unemployed & $21 / 52(40.0)$ & $31 / 52(60.0)$ & 0.005 \\
\hline & Artisan & $5 / 46(11.0)$ & $41 / 46(89.0)$ & \\
\hline & Farmer & $52 / 162(32.0)$ & $110 / 162(68.0)$ & \\
\hline \multirow{2}{*}{ Take fruit $\geq 3$ times per week } & Yes & $26 / 81(32.0)$ & $55 / 81(68.0)$ & 0.259 \\
\hline & No & $87 / 336(26.0)$ & $249 / 336(74.0)$ & \\
\hline \multirow{2}{*}{ Take breakfast before school } & Yes & $103 / 294(26.0)$ & $291 / 394(74.0)$ & 0.069 \\
\hline & No & $10 / 23(43.5)$ & $13 / 23(56.5)$ & \\
\hline
\end{tabular}

${ }^{1}$ Differences in characteristics of pupils in schools with and without school feeding were generated using Pearson's Chi-square. 
From Table 2, generally, no differences were observed in the mean age, weight, height, weight-for-age z-scores (WAZ), mid-upper arm circumference (MUAC)-for-age z-scores and body mass index (BMI)-for-age z-scores between pupils attending schools with and without the Ghana school feeding programme. However, pupils attending schools without the feeding programme were found to have significantly higher height-for-age mean zscores $(-0.28 \pm 1.2)$ compared to those attending schools with the feeding programme $(-0.64 \pm 1.0)$.

Results from the regression analyses presented in Table 3 showed that generally enrolment in schools implementing the Ghana school feeding programme did not significantly reduce the pupil's odds for underweight, stunting, thinness and overweight. In the bivariate analysis to determine the factors associated with underweight, it was observed that pupils in lower primary had three times increased odds for being underweight (AOR; 3.0, 95\% CI; 1.4-6.6, p=0.006) compared to their upper primary counterparts. Highest proportions of underweight were observed among pupils attending schools in the Lipke (25.4\%) and Akpafu $(20.0 \%)$ sub-districts. Pupils in the Lolobi sub-district recorded the lowest proportion $(5.0 \%)$ of underweight and hence had decreased odds for underweight, which was statistically significant (AOR; 0.2, 95\% CI; 0.03-0.8, $\mathrm{p}=0.007$ ). About $16.5 \%$ of the pupils living in rural areas were underweight as against $13.5 \%$ of those living in urban areas of the municipality. There was also a high proportion of underweight (24.4\%) among pupils aged 3-5 years compared to those within the ages of 6-12 years $(13.6 \%)$. However, there was no statistically significant association between underweight and sex, age, guardian's occupation, residency in rural or urban areas of the municipality, consumption of fruits at least three times per week and consumption of breakfast at home before leaving for school.

Table 2. Age and anthropometry of pupils attending schools with and without the Ghana school feeding programme

\begin{tabular}{|c|c|c|c|}
\hline Variables & School feeding $n=113($ Mean \pm SD $)$ & Non-school feeding $n=304($ Mean \pm SD) & P-value \\
\hline Age (years) & $8.6 \pm 2.6$ & $8.3 \pm 2.7$ & 0.3015 \\
\hline Weight (kg) & $25.2 \pm 8.6$ & $24.7 \pm 8.4$ & 0.6137 \\
\hline Height $(\mathrm{cm})$ & $125.4 \pm 15.3$ & $125.4 \pm 14.1$ & 0.9905 \\
\hline MUAC & 17.30 & 17.28 & 0.9255 \\
\hline WAZ & $-1.00 \pm 1.0$ & $-0.99 \pm 2.0$ & 0.9254 \\
\hline HAZ & $-0.80 \pm 0.1$ & $-0.48 \pm 1.1$ & 0.0057 \\
\hline MUAC z-score & $-0.81 \pm 0.7$ & $-0.63 \pm 1.0$ & 0.3902 \\
\hline BMI-for-age z-scores & $-0.53 \pm 0.78$ & $-0.54 \pm 1.0$ & 0.9385 \\
\hline
\end{tabular}

Table 3. Underweight among the pupils and related predicating factors

\begin{tabular}{|c|c|c|c|c|}
\hline Attribute & Variables & n/N(\%) & $\operatorname{AOR}(95 \% \mathrm{CI})$ & P-value \\
\hline \multirow{2}{*}{ Provided with school meals } & Yes & $14 / 113(12.4)$ & Reference & \\
\hline & No & $51 / 304(16.7)$ & $1.2(0.6-2.6)$ & 0.466 \\
\hline Sex & Female & $32 / 211(15.2)$ & $0.9(0.5-1.6)$ & 0.729 \\
\hline \multirow[t]{2}{*}{ Location } & Urban & $17 / 126(13.5)$ & Reference & \\
\hline & Rural & $48 / 291(16.5)$ & $1.7(0.6-4.8)$ & 0.288 \\
\hline \multirow{2}{*}{ Age (years) } & $3-5$ & $19 / 78(24.4)$ & $01.8(0.6-5.2)$ & 0.319 \\
\hline & $6-12$ & $46 / 339(13.6)$ & Reference & \\
\hline \multirow{6}{*}{ Sub-districts } & Agumatsa & $8 / 52(15.4)$ & $0.6(0.2-1.6)$ & 0.292 \\
\hline & Akpafu & $12 / 60(20.0)$ & $0.6(0.3-1.6)$ & 0.335 \\
\hline & Alavanyo & $10 / 60(16.7)$ & $0.7(0.3-1.8)$ & 0.471 \\
\hline & Likpe & $15 / 59(25.4)$ & Reference & 0.817 \\
\hline & Lolobi & $3 / 60(5.0)$ & $0.2(0.1-0.6)$ & 0.007 \\
\hline & Hohoe & $9 / 82(11.0)$ & 1 & 0.548 \\
\hline \multirow{5}{*}{ Guardian's occupation } & Formal & $4 / 22(18.2)$ & $1.3(0.4-4.4)$ & 0.720 \\
\hline & Petty trader & 17/134(12.6) & $0.6(0.3-1.3)$ & 0.203 \\
\hline & Unemployed & $6 / 52(11.5)$ & $0.4(0.1-1.3)$ & 0.144 \\
\hline & Artisan & $6 / 46(13.0)$ & $1.6(0.2-1.7)$ & 0.342 \\
\hline & Farmer & $32 / 162(19.8)$ & Reference & \\
\hline \multirow{2}{*}{ Takes fruit $\geq 3$ times per week } & Yes & $6 / 81(7.4)$ & Reference & \\
\hline & No & $59 / 336(17.6)$ & $2.0(0.8-5.3)$ & 0.147 \\
\hline \multirow{2}{*}{ Takes breakfast before school } & Yes & $63 / 394(16.0)$ & Reference & \\
\hline & No & 2/23(8.7) & $0.9(0.2-4.2)$ & 0.863 \\
\hline \multirow[b]{2}{*}{ Class } & Kindergarten & $23 / 112(20.5)$ & $1.9(0.6-6.4)$ & 0.279 \\
\hline & Lower primary & $32 / 158(20.3)$ & $3.0(1.4-6.6)$ & 0.006 \\
\hline
\end{tabular}

Estimates based on maximum likelihood ratio mutually-adjusted logistic regression. Data presented as n/N(\%) unless otherwise indicated. Final model was significant (Prob $>$ Chi-square $=0.0081)$. 
Table 4. Stunting among the pupils and related predicating factors

\begin{tabular}{|c|c|c|c|c|}
\hline Attribute & Variables & $\mathbf{n} / \mathbf{N}(\%)$ & AOR (95\%CI) & P-value \\
\hline \multirow{2}{*}{ Provided with school meals } & Yes & $15 / 113(13.3)$ & Reference & \\
\hline & No & $26 / 304(8.6)$ & $0.6(0.3-1.3)$ & 0.183 \\
\hline \multirow{2}{*}{ Sex } & Female & $17 / 211(8.1)$ & $0.7(0.3-1.3)$ & 0.265 \\
\hline & Male & $24 / 206(11.7)$ & Reference & \\
\hline \multirow{2}{*}{ Location } & Rural & $33 / 291(11.3)$ & $5.3(1.3-21.6)$ & 0.021 \\
\hline & Urban & $8 / 126(6.35)$ & Reference & \\
\hline \multirow{2}{*}{ Age (years) } & $3-5$ & $4 / 78(5.1)$ & $1.1(0.2-8.3)$ & 0.899 \\
\hline & $6-12$ & $37 / 339(10.9)$ & Reference & \\
\hline \multirow{6}{*}{ Sub-districts } & Alavanyo & $10 / 60(16.7)$ & $0.9(0.3-2.8)$ & 0.905 \\
\hline & Lipke & $10 / 59(17.0)$ & Reference & \\
\hline & Agumatsa & $8 / 52(9.6)$ & $2.5(0.1-1.6)$ & 0.215 \\
\hline & Lolobi & $2 / 60(3.3)$ & $0.1(0.02-0.6)$ & 0.009 \\
\hline & Gbi & $4 / 44(9.1)$ & $2.5(0.6-12.7)$ & 0.207 \\
\hline & Hohoe & $4 / 82(4.9)$ & 1 & \\
\hline \multirow{6}{*}{ Guardian's occupation } & Akpafu & $6 / 60(10.0)$ & $0.4(0.1-1.4)$ & 0.162 \\
\hline & Formal & $5 / 22(22.7)$ & $2.9(0.8-10.4)$ & 0.099 \\
\hline & Petty trader & $7 / 135(5.2)$ & $0.5(0.2-1.3)$ & 0.154 \\
\hline & Unemployed & $7 / 52(13.5)$ & $2.0(0.6-6.4)$ & 0.224 \\
\hline & Artisan & $6 / 46(13.0)$ & $1.6(0.5-5.1)$ & 0.389 \\
\hline & Farmer & $16 / 162(9.9)$ & Reference & \\
\hline \multirow{2}{*}{ Takes fruit $\geq 3$ times per week } & Yes & $8 / 81(9.9)$ & Reference & \\
\hline & No & $33 / 336(9.8)$ & $1.2(0.5-3.0)$ & 0.708 \\
\hline \multirow{2}{*}{ Takes breakfast before school } & Yes & $39 / 394(9.9)$ & $0.8(0.1-4.2)$ & 0.783 \\
\hline & No & $2 / 23(8.7)$ & Reference & \\
\hline \multirow{3}{*}{ Class } & Kindergarten & $5 / 112(4.5)$ & $0.2(0.03-1.2)$ & 0.081 \\
\hline & Lower primary & $17 / 158(10.8)$ & $0.7(0.3-1.6)$ & 0.385 \\
\hline & Upper primary & $19 / 147(12.9)$ & Reference & \\
\hline
\end{tabular}

Estimates based on maximum likelihood ratio mutually-adjusted logistic regression. Data presented as $\mathrm{n} / \mathrm{N}(\%)$ unless otherwise indicated. Final model was significant $($ Prob $>$ Chi-square $=0.0087)$.

Table 5. Thinness and overweight among the school pupils and related risk factors

\begin{tabular}{|c|c|c|c|c|c|c|}
\hline \multirow{2}{*}{ Variables } & \multicolumn{3}{|c|}{ Thinness } & \multicolumn{3}{|c|}{ Overweight/obesity } \\
\hline & $\mathrm{n} / \mathrm{N}(\%)$ & $\mathrm{RR}(95 \% \mathrm{CI})$ & P-value & $\mathrm{n} / \mathrm{N}(\%)$ & $\beta(95 \% \mathrm{CI})$ & P-value \\
\hline \multicolumn{7}{|l|}{ School meal } \\
\hline Yes & 2/113(1.770 & Ref. & & $4 / 113(3.54)$ & & \\
\hline No & $16 / 304(5.26)$ & $3.8(0.8-18.0)$ & 0.083 & $19 / 3.4(6.25)$ & $1.8(0.6-6.0)$ & 0.306 \\
\hline \multicolumn{7}{|l|}{ Sex } \\
\hline Female & $9 / 211(4.27)$ & $1.1(0.4-2.9)$ & 0.859 & $11 / 211(5.21)$ & $1.2(0.5-2.8)$ & 0.685 \\
\hline Male & $9 / 206(4.37)$ & Ref. & & $12 / 206(5.83)$ & & \\
\hline \multicolumn{7}{|l|}{ Location } \\
\hline Rural & 9/291(3.09) & $0.6(0.2-1.9)$ & 0.424 & $14 / 291(4.81)$ & $0.8(0.3-2.0)$ & 0.572 \\
\hline Urban & $8 / 126(6.35)$ & Ref. & & $9 / 126(7.14)$ & Ref. & \\
\hline \multicolumn{7}{|c|}{ Age of pupils (years) } \\
\hline $3-5$ & $1 / 78(1.28)$ & $0.4(0.02-6.0)$ & 0.512 & $5 / 78(6.41)$ & $1.8(0.3-13.0)$ & 0.539 \\
\hline $6-12$ & $17 / 339(5.01)$ & Ref. & & $18 / 339(5.31)$ & Ref. & \\
\hline \multicolumn{7}{|c|}{ Guardian's occupation } \\
\hline Formal & $1 / 22(4.55)$ & $1.1(0.1-11.0)$ & 0.913 & $2 / 22(9.09)$ & $2.1(0.4-12.0)$ & 0.392 \\
\hline Petty trader & $8 / 135(5.93$ & $1.3(0.4-4.7)$ & 0.650 & $8 / 135(5.93)$ & $1.4(0.4-4.4)$ & 0.685 \\
\hline Unemployed & $3 / 52(5.77)$ & $2.0(0.4-11.0)$ & 0.422 & $3 / 52(5.77)$ & $1.4(0.3-6.7)$ & 0.663 \\
\hline Artisan & $1 / 46(2.17)$ & $0.5(0.1-4.3)$ & 0.497 & $4 / 46(8.70)$ & $1.8(0.5-7.4)$ & 0.398 \\
\hline Farmer & $6 / 162(3.70)$ & Ref. & & $6 / 162(3.70)$ & Ref. & \\
\hline \multicolumn{7}{|c|}{ Takes fruit $\geq 3$ times per week } \\
\hline Yes & $5 / 81(6.17)$ & $1.0(0.3-3.5)$ & 0.960 & $4 / 81(4.94)$ & $0.7(0.2-2.3)$ & 0.551 \\
\hline No & $13 / 336(3.87)$ & Ref. & & $19 / 336(5.65)$ & Ref. & \\
\hline \multicolumn{7}{|c|}{ Takes breakfast before school } \\
\hline Yes & $16 / 394(4.06)$ & Ref. & & $21 / 394(5.33)$ & Ref. & \\
\hline No & $2 / 23(8.70)$ & $2.2(0.4-11.5)$ & 0.355 & $2 / 23(8.70)$ & $1.6(0.3-8.1)$ & 0565 \\
\hline \multicolumn{7}{|l|}{ Class group } \\
\hline Pre-school & $1 / 112(0.89)$ & $0.5(0.1-4.2)$ & 0.532 & $6 / 112(5.36)$ & $0.4(0.1-2.8)$ & 0.376 \\
\hline Class 1-3 & $8 / 158(5.06)$ & $0.9(0.3-2.6)$ & 0.857 & $6 / 158(3.80)$ & $0.5(0.2-1.4)$ & 0.164 \\
\hline Class 4-6 & $9 / 147(6.12)$ & Ref. & & $11 / 147(7.48)$ & Ref. & \\
\hline
\end{tabular}


The logistic regression analysis presented in Table 4 shows that pupils in the Lipke sub-district had the highest rate of stunting (17.0\%) followed by Alavanyo sub-district (16.7\%). Pupils attending schools in Lolobi sub-district had decrease odds for stunting compared to those attending school in Lipke sub-district (AOR; 0.1, 95\% CI; 0.02-0.6, $\mathrm{p}=0.009$ ). Besides this, pupils residing in rural areas were 5 folds more likely to be stunted compare to those in urban areas $(\mathrm{AOR}=5.3,95 \% \mathrm{CI}$; 1.3-21.6, $\mathrm{p}=0.021$ ). Furthermore, there was high proportion of stunting among boys (11.7\%) as against girls (8.1\%). Also, stunting in older pupils (6-12 years) was high (11.0\%) compared to younger ones (3-5years) $(5.1 \%)$. However, the differences in the level of stunting observed among boys and girls and among older and young children were not statistically significant.

The prevalence of thinness $(4.3 \%)$ and obesity $(5.5 \%)$ recorded were generally similar to what is expected in a normal population. However, obesity was high among pupils attending schools in urban areas (7.1\%) and among pupils in upper class $(7.5 \%)$ compared to those attending schools in rural areas (4.8\%) and in the lower primary $(3.8 \%)$ respectively. There was no statistically significant association between the various explanatory variables and thinness or obesity (Table 5).

\section{Discussion}

The purpose of this study was to assess effects of provision of school meals on the nutritional status of pupils enrolled in schools with and without school feeding programme. The key findings of the study were that there was high proportion of underweight (15.6\%). Further, pupils attending schools with and without school feeding programme had different proportions of underweight (12.4\% vs. $16.8 \%)$ and stunting (13.3\% vs. $8.6 \%)$. More to the point, pupils attending schools without school feeding programme were observed to have significantly high mean height-for-age z-scores compared to those attending schools with school feeding programme. High proportion of underweight was also observed in pupils attending schools in rural communities $(16.5 \%)$ as against those in urban areas (13.5\%).

Besides this, pupils residing in rural areas were about five folds more likely to be stunted compare to those residing in urban areas. It was also observed that pupils in lower primary had increased odds for underweight compared to those in the upper primary. Among the children enrolled in the two categories of schools, there were no statistically significant differences in the nutritional status indicators assessed in this study. Participation in the school-feeding programme was not statistical significant determinant of underweight, stunting, thinness and overweight levels.

The overall proportion of underweight observed in the present study is higher than the prevalence reported at the national level. According to Ghana Demographic and Health Survey (DHS), prevalence of malnutrition differs from one geographical area to another. However, the prevalence of underweight observed in this study is higher compared with what the DHS reported for children less than 5 years in 2014 [37] at the national level and in the
Volta region of Ghana where this study was conducted. Perhaps there are still pockets of hunger in the municipality where the study took place more especially among rural inhabitants. This notwithstanding reports have indicated that during the past six years, prevalence of stunting, underweight and wasting have reduced in Ghana $[2,3]$.

In general, the proportion of stunting and thinness were however low in the present study compared to other studies conducted in Ghana and elsewhere among school age children. For example, Appiah and Laar [32] in 2014 found the proportion of wasting and stunting to be $19.4 \%$ and $50.3 \%$ respectively in the Nkwanta South District of the Volta Region. Similarly, in 2013 , over $40 \%$ of stunting and $20 \%$ of wasting were observed among school children in rural Ethiopia [38].

Studies conducted to evaluate the impact of provision of school foods on nutritional status have shown positive $[23,35]$ but more often, less conclusive $[4,8,26]$ outcomes relating to effects of the programme on the prevalence of under nutrition among participating and non-participating school children. In the study conducted by Abizari in Ghana [31], although there were no significant differences in stunting, underweight and thinness levels among participants and non-participants, mean probability of adequacy of micronutrients evaluated was significantly higher among children enrolled in SFP schools.

These findings are consistent with the findings from the present study, which found no statistical significant difference in nutritional status indicators (underweight, stunting, thinness and overweight) between pupils attending schools with and without school feeding although differences were observed between the two groups in the prevalence of the various indicators. The widespread poor quality of school meals served $[15,16,36]$ could be a possible cause of minimal contribution of school meals to the growth of beneficiaries.

On the contrary the proportion of underweight was high among pupils attending schools without school feeding programme compared to those in schools with school feeding programme. This is in conformity with other studies in Ghana, which reported better nutritional status among children attending schools with school feeding programme compared to those in schools without school feeding programme [4,32].

In addition to this, rural-urban differences in underweight and stunting were also observed. The study showed that there was high proportion of underweight among pupils attending schools in rural areas compared to urban areas. Further, pupils in rural areas were five folds more likely to be stunted as compared to those in the urban areas. This finding is in agreement with the findings of the Ghana demographic and Health survey in children under-five years, which show higher proportion of underweight among rural children compared to those in urban areas [37]. Another study in Ethiopia [38] also found high proportion of malnutrition among rural school children compared to their urban counterparts.

The better nutritional status of pupils in urban communities in the present study is also in conformity with those of other studies among school children in Nigeria [39] and other developing countries. The differences observed might be due to differences in the 
socio-economic status of the parents [34]. In addition, the usual higher prevalent rates of intestinal parasites especially among rural children compared with urban dwellers and the likelihood of inadequate food intake in the rural areas could contribute to the disparity in the nutritional status between the children in both communities [40].

Moreover, there was a high proportion of overweight among pupils attending schools in urban areas compared to those in rural areas. This finding seemed to follow the same patterns as adult over-nutrition in Ghana, which is higher among urban population than rural population [41]. This could be due to the changes in life style, diet, urbanization, and reduced active commuting to school, use of energy saving devices and increasing sedentary games such as computer games and television watching that creates an 'obesogenic' environment [42].

Pupils in lower primary, usually between the ages of 6 to 9 years, were more prone to being underweight. This finding is in line with other studies conducted in other developing countries. For example a study in India showed that underweight and stunting was high among children in the age groups of 5-6 years while stunting was high in children between the ages of 6-8 years [43]. Unlike findings from Appiah and Laar [32], neither sex of child nor age was a predictor for malnourishment.

The possibility of a longitudinal study design providing an in-depth outcome on impact of the Ghana school feeding programme in the Hohoe municipality cannot be ruled out. The absence of a baseline data also made it impossible to compare present nutritional status indicators with what pertained at the inception of the programme. This would have given a better perspective on the impact of the programme. Nonetheless, the comparative component of the study design still provides some useful insights about impact of the feeding programmes on school children's anthropometry.

\section{Conclusion}

On the whole, the study did not show any statistical significant difference in the nutritional status indicators (underweight, stunting, thinness and overweight) between children attending schools with school feeding programmes and those in schools without school feeding programmes. Nonetheless, there were higher rates in some of the indices such as thinness and underweight among pupils in schools where the feeding programme was non-existent. Therefore, findings from this study has provided to a large extent some evidence to prove that although there may not be significant differences in the anthropometric indicators of children participating and not participating in school feeding programmes, enrolment of children in schools where they are served school meals may make marginal contributions towards improving their nutritional status.

\section{Acknowledgements}

The authors thank the Hohoe municipal directors of education and health for granting permission to carry out the study, and also all school heads and class teachers in the public basic schools within the municipality where the study was conducted. We appreciate parents and guardians who consented for their wards to be part of the study and assisted with eliciting information from the younger pupils.

\section{Authors Note}

P. Atito and F. Agbozo designed the study. P. Atito did data collection and entry. A. Abubakari and F. Agbozo analyzed the data and drafted the paper.

\section{Conflict of Interest}

The author(s) declared no potential conflicts of interest with respect to the research, authorship, and/or publication of this article.

\section{Funding}

We did not receive any funding for this research.

\section{List of Abbreviations}

SFP - school feeding programme

GSFP - Ghana school-feeding programme.

\section{References}

[1] UNICEF: The State of the World's Children 2015: Reimagine the Future: Innovation for Every Child. In. New York, USA: United Nations Children's Fund; 2015: 116.

[2] Ghana Statistical Service: Ghana Demographic and Health Survey Key Indicators. In. Accra, Ghana: Ghana Statistical Service, Ghana Health Service, Ghana, The DHS Program, ICF International, Rockville, Maryland, USA; 2015.

[3] Ghana Statistical Service: Ghana Demographic and Health Survey 2008. In. Accra, Ghana: (Ghana Health Service; Ghana Statistical Services: Ghana Health Service Accra, Ghana and ICF Macro Calverton, Maryland, U.S.A. ; 2008.

[4] Danquah A, Amoah A, Steiner-Asiedu M, Opare-Obisaw C: Nutritional status of participating and non-participating pupils in the Ghana School Feeding Programme. Journal of Food Research 2012, 1(3):p263.

[5] WFP: State of School Feeding Worldwide. In. Rome, Italy World Food Programme

http://home.wfp.org/stellent/groups/public/documents/communicat ions/wfp257481.pdf (accessed on December 2014); 2013.

[6] Government of Ghana: Ghana School Feeding Programme Annual Operating Plan 2013. In. Accra, Ghana: Ghana School Feeding Programme Secretariat; Ministry of Local Government \& Rural Development

http://schoolfeeding.gov.gh/index.php?option=com docman\&task $=$ doc_details\&gid $=14 \& \mathrm{tmpl}=$ component\&Itemid $=112 \quad($ accessed on September 2014) 2013.

[7] Alderman H, Bundy D: School feeding programs and development: are we framing the question correctly? The World Bank Research Observer 2011:lkr005.

[8] Jomaa LH, McDonnell E, Probart C: School feeding programs in developing countries: impacts on children's health and educational outcomes. Nutrition reviews 2011, 69(2):83-98.

[9] Belot M, James J: Healthy school meals and educational outcomes. Journal of health economics 2011, 30(3):489-504. 
[10] Afridi F: The impact of school meals on school participation: evidence from rural India. Journal of Development Studies 2011, 47(11):1636-1656

[11] Singh A, Park A, Dercon S: School meals as a safety net: an evaluation of the Midday Meal scheme in India. Economic Development and Cultural Change 2014, 62(2):275-306.

[12] Gelli A: School Feeding and Girls' Enrollment: The Effects of Alternative Implementation Modalities in Low-Income Settings in Sub-Saharan Africa. Frontiers in Public Health 2015, 3:76.

[13] Bundy DA, Drake LJ, Burbano C: School food, politics and child health. Public Health Nutrition 2013, 16(06):1012-1019.

[14] Akbar M: Pupils' satisfaction with school mid-day meal program. British Food Journal 2015, 117(7):1933-1948.

[15] Sidaner E, Balaban D, Burlandy L: The Brazilian school feeding programme: an example of an integrated programme in support of food and nutrition security. Public Health Nutrition 2013, 16(06):989-994.

[16] Shin D: Analysis of micromineral contents of school meals Nutrition Research and Practice 2014, 8(4):439-444.

[17] Wall-Bassett ED, Kunkel ME, Guiste PK, Gerard PD, Fang X, Prevost JL: Anthropometric Status and Nutrient Intake of Dominican Children in Schools With and Without School Feeding Programs. Topics in Clinical Nutrition 2012, 27(2):85-94.

[18] Joulaei H, Nwagwu E, Nasihatkon A, Azadbahkt L, Shenavar R, Keshtkar V, Ahmadi SM: To assess the effects of nutritional intervention based on advocacy approach on malnutrition status among school-aged children in Shiraz. Journal of Research in Medical Sciences : The Official Journal of Isfahan University of Medical Sciences 2013, 18(9):739-745.

[19] Buttenheim AM, Alderman H, Friedman J: Impact evaluation of school feeding programs in Lao PDR. World Bank Policy Research Working Paper 2011(5518).

[20] Adrogué C, Orlicki ME: Do In-School Feeding Programs Have an Impact on Academic Performance? The Case of Public Schools in Argentina. Education Policy Analysis Archives/Archivos Analiticos de Políticas Educativas 2013, 21:1-20.

[21] Chepkwony BC, Kariuki BM, Kosgei LJ: School feeding program and its impact on academic achievement in ECDE in Roret Division, Bureti District in Kenya. Journal of Emerging Trends in Educational Research and Policy Studies 2013, 4(3):407-412.

[22] McEwan PJ: The impact of Chile's school feeding program on education outcomes. Economics of Education Review 2013, 32: 122-139.

[23] Nkhoma OW, Duffy ME, Cory-Slechta DA, Davidson PW, McSorley EM, Strain J, O’Brien GM: Early-stage primary schoo children attending a school in the Malawian School Feeding Program (SFP) have better reversal learning and lean muscle mass growth than those attending a non-SFP school. The Journal of nutrition 2013, 143(8):1324-1330.

[24] Abotsi AK: Expectations of School Feeding Programme: Impact on School Enrolment, Attendance and Academic Performance in Elementary Ghanaian Schools. Abotsi AK (2013) "Expectations of School Feeding Programme: Impact on School Enrolment, Attendance and Academic Performance in Elementary Ghanaian Schools" British Journal of Education, Society \& Behavioural Science 2013, 3(1):76-92.

[25] Oduro-Ofori E. and Gyapong AY: The Contribution of the Ghana Schools Feeding Programme to Basic School Participation: A Study of Selected Schools in the Kwaebibirim District of Ghana. Developing Country Studies 2014, 4(19):40-50.

[26] Nyarko SH: Assessment of the school feeding programme in Ghana: A study of primary schools in the Abura-AsebuKwamankese district in the Central region of Ghana. International Journal of Research in Social Sciences 2014, 4(2):13.

[27] Obeng-Denteh W, Gyasi-Agyei K, Boateng L, Owusu B, Asiedu K, Antepim O: A Mathematical Modeling of School Feeding
Programme in the Asem-Kumasi Cluster of Schools in Ashanti Region of Ghana. British Journal of Mathematics \& Computer Science 2014, 4(5):704.

[28] Quaye W, Essegbey G, Frempong G, Ruivenkamp G: Understanding the concept of food sovereignty using the Ghana School Feeding Programme (GSFP). International Review of Sociology-Revue Internationale de Sociologie 2010, 20(3): 427-444.

[29] Shaibu AF, Al-hassan RM: Analysis of Factors Influencing Caterers of the Ghana School Feeding Programme to Purchase Rice from Local Farmers in the Tamale Metropolis, TolonKumbungu and Karaga Districts. AGRIS On-line Papers in Economics and Informatics 2014, 6(2):77-87.

[30] Essuman A, Bosumtwi-Sam C: School feeding and educational access in rural Ghana: Is poor targeting and delivery limiting impact? International Journal of Educational Development 2013, 33(3): 253-262.

[31] Abizari A-R, Buxton C, Kwara L, Mensah-Homiah J, ArmarKlemesu M, Brouwer ID: School feeding contributes to micronutrient adequacy of Ghanaian schoolchildren. British Journal of Nutrition 2014, 112(06): 1019-1033.

[32] Appiah KP and Laar Laar A: Nutritional status of school-age children in the nkwanta south district-volta region of ghana. European Scientific Journal 2014, 10(30).

[33] Gelli A, Espejo F: School feeding, moving from practice to policy: reflections on building sustainable monitoring and evaluation systems. Public Health Nutrition 2013, 16(06):995-999.

[34] Ghana Statistical Service: 2010 Population and Housing Census Final Results. In. Accra, Ghana: Ghana Statistical Service http://www.statsghana.gov.gh/docfiles/2010phc/2010 POPULATI ON_AND_HOUSING_CENSUS_FINAL_RESULTS.pdf (accessed on June 2014); 2012.

[35] Falade OS, Otemuyiwa I, Oluwasola O, Oladipo W, Adewusi SA: School Feeding Programme in Nigeria: The Nutritional Status of Pupils in a Public Primary School in Ile-Ife, Osun State, Nigeria. Food and Nutrition Sciences 2012, 3(05):596.

[36] Harding K, Marquis G, Colecraft E, Lartey A, Sakyi-Dawson O Participation in communal day care centre feeding programs is associated with higher diet quantity but not quality among rural Ghanaian children. African Journal of Food, Agriculture, Nutrition and Development 2012, 12(1):5802-5821.

[37] GSS/GHS: Ghana Demographic nad Helath Survey, Key indicators. In. Accra, Ghana: GSS/GHS/ DHS Program ICF International; 2014: 1-45.

[38] Herrador Z, Sordo L, Gadisa E, Moreno J, Nieto J, Benito A, Aseffa A, Canavate C, Custodio E: Cross-sectional study of malnutrition and associated factors among school aged children in rural and urban settings of Fogera and Libo Kemkem districts, Ethiopia. PloS one 2014, 9(9):e105880.

[39] Oninla SO, Owa JA, Onayade AA, Taiwo O: Comparative Study of Nutritional Status of Urban and Rural Nigerian School Children. Journal of Tropical Pediatrics 2007, 53(1):39-43.

[40] Ogbonna C OS, Okonji MC.: Intestinal wormsand nutritional status of under-fives in Jos, Nigeria: any relationship? Nig J Clin Pract 2004, 7

[41] Konan ER: Epidemiology of adiposity in Ghanaian women of childbearing age: a comparative study between urban and rural place of residence. School of Public Health: Georgia State University; 2010.

[42] Popkin BM: Using research on the obesity pandemic as a guide to a unified vision of nutrition. Public Health Nutrition 2005, 8: 724-729.

[43] Srivastava A, Mahmood SE, Srivastava PM, Shrotriya VP, Kumar B: Nutritional status of school-age children - A scenario of urban slums in India. Archives of public health $=$ Archives belges de sante publique 2012, 70(1): 8 . 